\title{
Competence-Oriented, Data-Driven Approach for Sustainable Development in University-Level Education
}

\author{
Szabina Fodor ${ }^{1, *}$, Ildikó Szabó ${ }^{2}$ (1) and Katalin Ternai ${ }^{2}$ \\ 1 Department of Computer Science, Institute of Information Technology, Corvinus University of Budapest, \\ Fővám tér 13-15, 1093 Budapest, Hungary \\ 2 Department of Information Systems, Institute of Information Technology, Corvinus University of Budapest, \\ Fővám tér 13-15, 1093 Budapest, Hungary; ildiko.szabo2@uni-corvinus.hu (I.S.); \\ katalin.ternai@uni-corvinus.hu (K.T.) \\ * Correspondence: szabina.fodor@uni-corvinus.hu; Tel.: +36-1-482-7468
}

check for updates

Citation: Fodor, S.; Szabó, I.; Ternai, K. Competence-Oriented, Data-Driven Approach for Sustainable Development in University-Level Education. Sustainability 2021, 13, 9977. https://doi.org/10.3390/ su13179977

Academic Editors: Aurélien Decamps, Benoit Martimort-Asso and Carine Royer

Received: 29 June 2021

Accepted: 30 August 2021

Published: 6 September 2021

Publisher's Note: MDPI stays neutral with regard to jurisdictional claims in published maps and institutional affiliations.

Copyright: (c) 2021 by the authors. Licensee MDPI, Basel, Switzerland. This article is an open access article distributed under the terms and conditions of the Creative Commons Attribution (CC BY) license (https:// creativecommons.org/licenses/by/ $4.0 /)$.

\begin{abstract}
Higher education has a number of key roles to play in accelerating progress toward sustainability goals. It has a responsibility to provide and teach curricula that are tailored to labor market needs, to help change people's attitudes and motivation toward sustainability, and to reduce inequalities between different students. Course leaders and developers of curricula should monitor and assess these needs in order to improve their curricula from time to time. In the present work, we describe a data-driven approach based on text-mining techniques to identify the competences required for a given position based on job advertisements. To demonstrate the usefulness of our suggested method, the supply chain management occupation was selected as the supply chain is a constantly changing domain that is highly affected by green activities and initiatives, and the COVID-19 pandemic strongly influenced this sector, as well. This data-driven process allowed the identification of required soft and hard skills contained in job descriptions. However, it was found that some important concepts of green supply chain management, such as repair and refurbishment, were only marginally mentioned in the job advertisements. Therefore, in addition to labor market expectations, a business process model from relevant green supply chain management literature was developed to complement the required competences. The given new techniques can support the paradigm shift toward sustainable development and help curriculum developers and decision makers assess labor market needs in the area of sustainability skills and competences. The given result can serve as an input of outcome-based training development to design learning objective-based teaching materials.
\end{abstract}

Keywords: sustainability competences; higher education; knowledge for change; data-driven approach; curriculum planning

\section{Introduction}

Sachs et al. [1] identified the following six transformations as modular building-blocks of achieving Sustainable Development Goals (SDG): (1) education, sex, and inequality; (2) health, well-being, and demography; (3) energy decarbonization and sustainable industry; (4) sustainable food, land, water, and oceans; (5) sustainable cities and communities; and (6) digital revolution for sustainable development. Developing education systems were emphasized at the first transformation mainly, but all transformations need a cognitive shift in human minds to change or nurture their norms and behaviors for facilitating diplomatic discourse around mutual points and elaborating activities to attain SDGs.

Education has key roles in improving humans' skills and competences. Humans express willingness to make our world sustainable if they possess enough knowledge, motivation about these goals. They have a responsibility in providing and teaching such curricula that improve students' competences and make them emotionally committed to sustainability. Higher education trains future entrepreneurs, decision makers, visionary 
members who can manage or adjust regulatory environments, business processes, or social activities of companies. Nevertheless, education can also play a role in diminishing inequality in the labor market if learning outcomes provided by training programs fit labor market needs and training programs are open for a wide audience. Digital technologies have either disruptive or renewing effects on the labor market. Several studies analyse factors influencing the reshaping of job roles and provide a toolset to predict future occupations. Meanwhile, digital technologies generate opportunities for education institutes to use collaborative, e-learning, or other platforms to transfer knowledge in an efficient manner. These platforms help to reach people wishing to learn from everywhere if they have appropriate devices and Internet connections. The coronavirus pandemic accelerated this digital revolution of education.

In summary, education institutes need to possess curricula and training programs fitting to labor market needs and digitalized teaching environments to help in changing human attitude and motivation toward sustainability and in diminishing inequality by attracting students from remote places. This paper aims to facilitate the work of curriculum developers (program and course leaders, lecturers). It investigates what methods fit to collecting and structuring data from external sources (job ads or literature) to enhance curriculum development. Guidelines and technologies in sustainability transform the business processes at the adopting companies, which induce changes in competence needs in the labor market. Curriculum developers have to keep up with the knowledge about actual and possible changes that can be detected in external sources such as job ads, peer-reviewed journals, books, etc. Information and data extracted from these sources in structured format facilitate decision making during curriculum development. Data can be competences or knowledge areas taken from external sources and their regional, organizational, or industrial contexts.

Methods for data extraction differ in terms of the development process, the domain, and the external data sources used to integrate sustainability knowledge into the curriculum. The theoretical background presents the four essential pillars of curriculum development to elaborate an effective method (see in Figure 1). Accordingly, Section 2 is divided into the following four subsections:

- Presenting the importance of competence-based education in sustainability in higher education institutions (HEIs);

- Showing related work on how to process external sources, such as job advertisements, to extract expected knowledge and skills;

- Introducing green supply chain management as the domain of our empirical study; and

- Synthesizing the above results to create a self-developed competence framework. In empirical research, this framework is used as an analytical lens.

The research questions formulated in Section 3 aim to investigate three issues of importance to curriculum developers. They highlight the applicability of our proposed data-driven methods as these methods help to obtain a better understanding of the recent competences and skills required by employers from data extracted from online job advertisements. Section 4 presents our data-driven methodology. In the first part of the text-based analysis, text-mining techniques such as phrase frequency and topic modeling were used to determine soft skills from job ads. In the second part, the grammatical structure of words was considered to detect hard skills. Sections 5 and 6 present our results and discussion. Concepts of green supply chain management, such as repair, remanufacturing, refurbishment, etc., were only marginally mentioned in job advertisements, although they should be emphasized in higher education curricula. To fill this gap, the knowledge areas not emphasized by job ads were added in a structured format with developing a business process model from relevant literature. Conclusions are drawn at the end of the paper. 


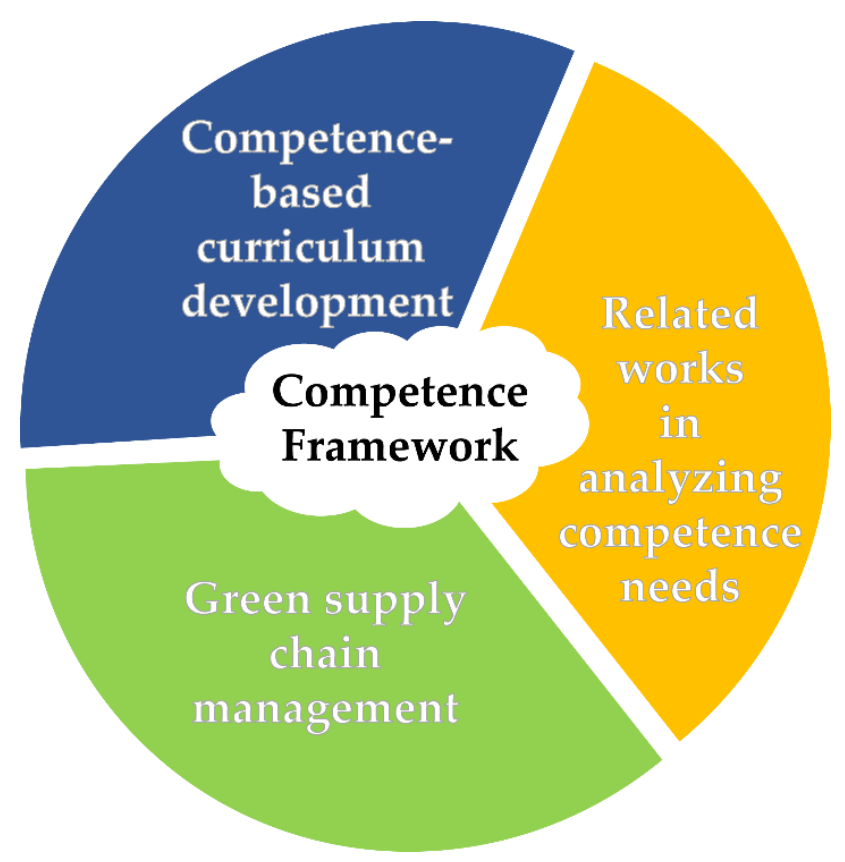

Figure 1. The structure of the literature review (Source: prepared by the authors).

\section{Background}

\subsection{Competence-Based Curricula Development}

Education has a key role in making sustainability phenomena understandable, acceptable, and adaptable by humans. Quality education is emphasized among the 17 Sustainable Development Goals. The predecessors of SDGs were the Dakar Framework for Action and Millennial Development Goals. These initiatives assigned implicit, supportive roles to higher education. Countries focused on financing primary and secondary education instead of higher education and vocational training to obtain a greater return on their value. Meanwhile, universities began to develop their common policies but only actions supported financially became true. Currently, higher education has three missions: nurturing and teaching generations to be committed to sustainability, doing scientific research, and providing community services to be a catalyzer in an innovative society [2]. Curricula are the only medium to facilitate these endeavors. Outcome-based curricula or training development gains much attention currently. Outcome-based education (OBE) concerns what students will be able to do at the end of their learning pathways, experiences, and how this is fostered with well-developed curricula, instructions, reporting, and assessment [3]. In a broader sense, it is about how influencing factors (infrastructure, fundraising, partnership, etc.) have to be organized in the education system. It is rooted in Spady's work, which determined four principles: clarity of focus, expanded opportunity, high expectations, and design down. These principles help to design flexible learning paths along which teachers and students can work cooperatively toward achieving expected outcomes [4]. OBE emphasizes expected competencies demonstrated by students as outcomes whose acquisition depends on students' thinking or cognitive styles [5].

Learning outcomes described by competencies are also the cornerstones of these reforms. Competence concept on the supply side of the labor market is a common denominator in developing curricula aiming at acquiring sustainable-specific concepts and standardizing the process to enhance mobility. It is also on the demand side of the labor market in developing frameworks to connect organizations, individuals, and jobs by offering compliance between job-related competence expectations and individual competence resources [6-8].

Competence concept is distinguished based on its context, experts' or scientific researchers cognitive and thinking process, and applied terminology. It is not surprising that this concept is confused with skills, proficiency, knowledge, and other terms in both 
colloquial language and literature. It roots in the Latin word "Compete", which means the ability to do something. Competence and competency have different meanings in the interpretation of Rowe [9]. According to Rowe [9], the first term is used for describing the satisfactory application of practical skills while putting an emphasis on the achieved performance standards; while in the second case, the behavior leading to the activities is emphasized. In other words, in the case of the word competence, "What is a human capable of?", while in the case of competency, "How a human is capable of doing?" is emphasized. This paper uses them interchangeably.

Hecklau et al. [10] refer to four competence categories. Technical competences are knowledge, skills, and abilities connected to work. Personal competences consist of motivations and attitudes. Social competences are abilities to cooperate, communicate with other people. Methodological competences are to support decision making and problem solving. Grundke et al. [11] define cognitive and non-cognitive skills. Wikle and Fagin [12] consider skills as expertise and/or knowledge to complete a task, including vernacular, personal attributes, as well. They distinguish hard/technical and soft skills as competences. Hard skills are learned or professional competencies; soft skills are generic ones. Lippman et al. [13] defined soft skills on page 809 as "a broad set of skills, competencies, behaviours, attitudes, and personal qualities that enable people to effectively navigate their environment, work well with other and perform well". Soft skills are even referred to as "life and 21st century skills" [14]. Bianchi states that education usually thinks in competences; meanwhile, the world of labor requires skills [15]. This paper focuses on both approaches simultaneously. It introduces a competence framework including sustainability competences connected to supply chain managers to support developers of training programs in expressing learning outcomes or objectives. It classifies the elements of this framework into hard skills (meaning learned, professional competencies) and soft skills. This framework (see in Section 2.4) is employed in this sense to investigate competence needs in job ads.

\subsection{Related Works in Analyzing Competence Needs}

Job advertisements are valuable indicators of the knowledge and skills desired by employers. A data-driven approach to analyse the content of job ads allows gaining valuable insights into the demand for recent knowledge, skills, and personal attributes. However, Carnevale et al. [16] argue that job advertisement data may mislead labor demand analyses. Fluctuations in the number of job advertisements do not necessarily reflect the changes in labor market demand. Furthermore, it is observed that highly skilled workers are more likely to be sought online than less-skilled workers. In addition, some advertisements do not represent actual vacancies but are used to collect data on applicants. There is no single universal job portal; many websites offer this service with different data formats. Therefore, data processing requires a big data infrastructure and precise algorithms to ensure consistent data analysis. Nevertheless, researchers [17-21] are keen to use job portal data to gain insights into actual skills needs and analyse trends.

International organizations such as OECD (Organization for Economic Co-operation and Development) [22] and CEDEFOP (European Centre for the Development of Vocational Training) have a long history in examining the labor market. The OECD Skills for Jobs database (https:/ / www.oecdskillsforjobsdatabase.org [accessed on 15 June 2021]) contributes to analyse skill gaps and mismatches based on five sub-indices: wage growth, employment growth, hours worked growth, unemployment rate, under-qualification growth. Quantitative methods are applied by CEDEFOP Skill Forecast [23] to predicate future trends in sectors, occupations, and qualifications. Skill-OVATE (Skills Online Vacancy Analysis Tool for Europe) is an online vacancy analysis tool to reflect the competence needs of employers based on data fetched from job portals, employer's portals, etc., but only within a limited time. Burning Glass Technologies uses a web crawler to collect 70 variables of job ads from 40,000 job boards and company sites. De-duplications are executed to create a consistent database. The usability of this data set in policy-data analysis was investigated by Cammeraat and Squicciarini in the OECD report [24]. Researchers thinking on a smaller 
scale are concerned with regional and temporal changes in the competence needs associated with particular occupations (e.g., business analyst [25], data scientist [26], functional controller [27], Corporate Social responsibility professional [28], logistic manager [29]), or changes in the structure of the labor market influenced by external factors (e.g., closures due to the COVID-19 pandemic [30]).

The applied methods are also very different in terms of the data used and the techniques and software used to process them. Online job postings contain structured data (publishing date, salary, location, etc.) and free text, i.e., unstructured data (job title, job description, company information, etc.). Natural language processing (NLP) is used to transform all this data into normalized, structured data suitable for analysis. NLP employs a variety of methodologies to process the text can be found built-in in various software such as Rapidminer, SPSS Statistics, or custom programs that can be developed to implement them. Having consistent data sets, descriptive statistics, and advanced statistical approaches, and text-mining algorithms can be applied to find hidden patterns behind the data. A data-driven approach can highlight how job ads reflect the need for competences in sustainability. This computer-based solution supports decision makers (program and course leaders) with information on the actual needs of the labor market and allows them to discover different latent connections, such as the relationship between sustainability tasks and positions.

It is worth mentioning that the sustainability aspects are presented in different ways for each position, and these differences should be reflected in the curricula. Thus, we determined a specific area, supply chain management, to show how our solution can be used to develop new curricula and to refresh existing ones. The choice of supply chain management is motivated by the fact that "supply chains must ensure sustainable resource use and reduce pollution" [1] (p. 809), which is achieved by professionals with green skills, such as supply chain, logistics, and transportation managers [15].

\subsection{Green Supply Chain Management}

The importance of supply chain sustainability has grown over the past decades. The growing level of attention toward global warming, reduction in non-renewable resources, and pollution warns organizations to minimize environmental impact by integrating environmental concerns into their supply chain practices. The integration of environmental aspects, sustainability, and specifically green initiatives into supply chain management (SCM) operations is referred to as green supply chain management (GSCM) [31]. GSCM has been established as an important discipline in the academic world, and its literature is growing exponentially [32].

GSCM has its roots in both SCM and environment management. The "green" component involves the impact and relationships between SCM and the natural environment. GSCM can be defined as the integration of environmental management systems [33] into the supply chain process, including collaboration with customers, suppliers, and logistics service providers to share information and knowledge with an aim to improve environmental performance [34,35]. GSCM is also defined in the literature as the integration of environmental considerations within an organization into sustainable SCM, and its role ranges from product design to green procurement to integrated green supply chains [36,37].

GSCM is also defined in the literature as integrating environmental concerns into the inter-organizational practices of sustainable SCM and has ranged from product design, green purchasing to integrated green supply chains, including reverse logistics.

Porter and Linde [38] explained the fundamentals of greening as competitive initiatives, such as investments in greening, can be resource-saving, waste-eliminating, and productivity-improving. Expanding sustainability across the supply chain means a promising and effective approach to bringing innovation and practice into industrial operations [39]. In spite of the high investments in GSCM practices, they can improve both economic and environmental performance [40,41]. The benefits, such as saving energy, 
reducing waste, and increasing operational efficiency and corporate image, can outweigh the costs [42].

Green supply chain practices (GSCP) are the actions that translate the GSCM thoughts into operations. There are many GSCP that can be found in the literature: collaboration with suppliers to reduce dangerous materials, internal management support, collaboration with customers and suppliers and investment recovery [42], reverse logistics, green purchasing, green design, and product recovery and reuse of used products [43]. The growing importance of GSCM is driven by the decay of the environment, for example: decreasing raw material resources, overflowing landfills, and increasing levels of pollution. Therefore, the GSCM encompasses practices such as reduce, reuse, rework, refurbish, reclaim, recycle, remanufacture, reverse logistics, etc. GSCM can reduce the ecological impact of industrial activity, reserving quality, cost, reliability, performance, or energy use efficiency.

We have taken into account the categorization of GSCP by Srivastava [33] (see in Figure 2). Around 1500 books, articles from journals, and edited volumes had been studied to develop it. The purpose of the categorization was to understand different problem contexts of GSCM, their interactions, and relationships in an easier way. The classification presents a well-defined and clear picture, but it is not rigid, and there may be many overlaps in it. Green operations involve all operational aspects related to reverse logistics and network design, green manufacturing and remanufacturing, and waste management.

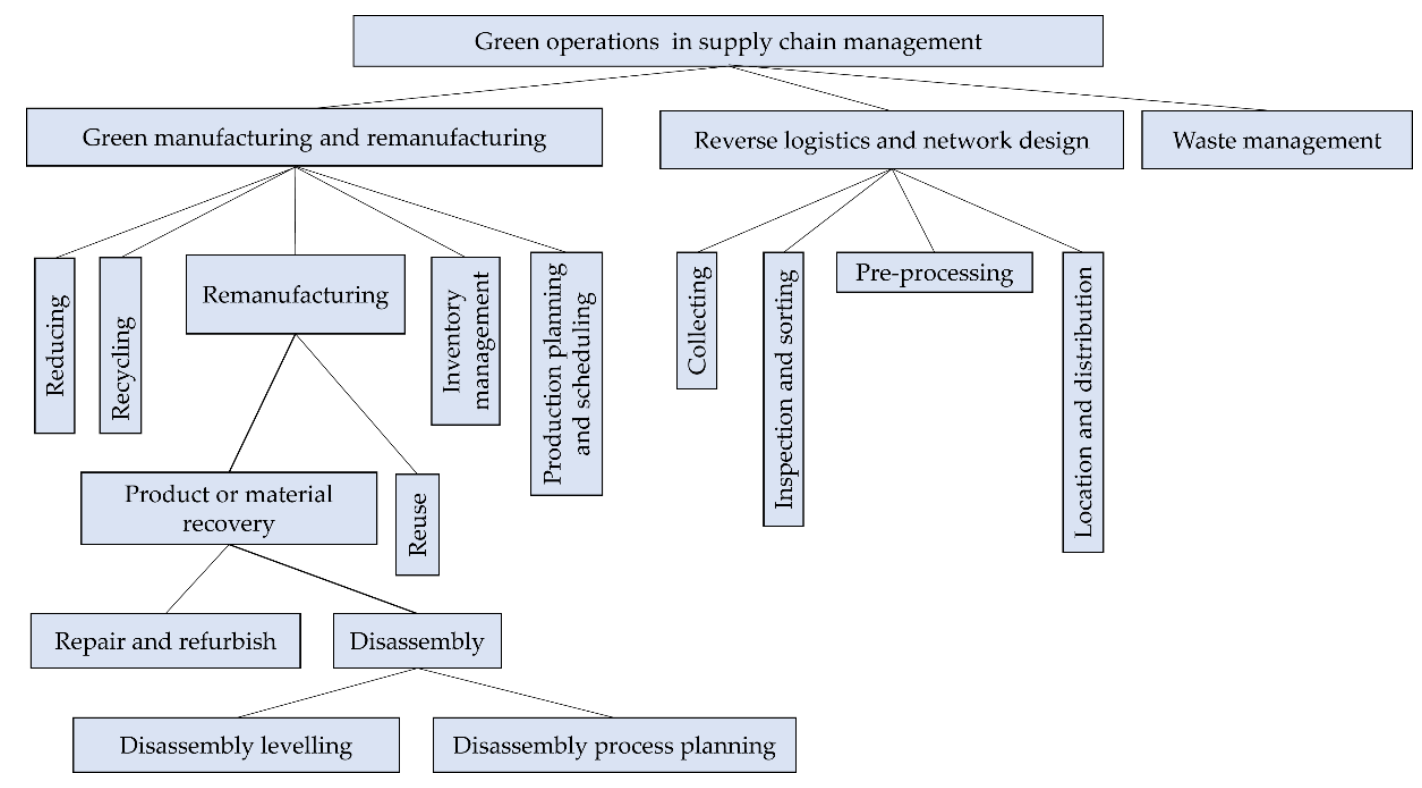

Figure 2. Green operations in SCM based on Srivastava classification [33].

\subsection{Competence Framework in Supply Chain Management}

A literature review elaborated by Bianchi analyzed and synthetized different competence approaches in sustainability from the point of view of education and the world of labor. Sustainability represents a long-term goal, while sustainable development supports the progress on this road. Education for sustainable development participates in these supporting processes by equipping people with knowledge, skills, attitude, and value in sustainability through their life [15]. Digital technologies in teaching such as MOOC courses, communication software (MS Teams, Zoom, etc.) facilitate these endeavors by making curricula and training programs accessible in a remote way while learning analytics informs students about their progress in competence development. Sustainability ideas, concepts, visions can be transferred to humans' thinking process by using materials and teaching methods built on these technologies if outcomes of the learning processes are clearly stated. These technologies are not magic wands to improve any competence. The type of competences (knowledge, skill, attitude, or value), the topic, the learners' cognitive 
and learning styles, among other factors, determine how to use these technologies. There is a terminological diversity in the field of competences both in general and in sustainability.

This paper uses the domain of green supply chain management to show how sustainability competences can be integrated into higher education curricula to meet labor market requirements. Corresponding competence frameworks [44-49] were used to elaborate our version. First of all, the frameworks of Brundiers [45] and MacDonald [48] were aligned. Brundiers conducted a Delphi study to collect experts' thoughts and synthetized them into their sustainability competence framework that is an extended version of the work of Wiek et al. [49] MacDonald et al. [48] interviewed 26 sustainability managers in Canada to discover 11 sustainability manager competences [15]. No peculiar difference was discovered between them.

In the second step, the framework of Mageto and Luke [44] was selected to align with the version of Brundiers [45]. It was created to supply chain managers based on literature reviews in that data were obtained by content analysis [44]. In this step, competences in sustainability and for supply chain managers were merged. The subcategories of Mageto and Luke were extended with elements from Brundiers' framework. Interpersonal and intrapersonal competences concern with human behaviors, which justified their connection. Other categories (e.g., cross-functional coordination, HRM, etc.) were aligned to the main categories (e.g., management) based on our expertise in these fields. At the end, a conceptual model (an ontology) was chosen to add more special aspects to this framework (see in Table 1).

Table 1. Summary of our conceptual model for supply chain managers' competences in sustainability based on the work of [44-47]. In the first column, G stands for general, and SCM stands for supply chain manager, which means that the current competency is related to the specific occupation only or is generally expected. The green background indicates that the given competence is a soft skill. (Source: prepared by the authors).

\begin{tabular}{|c|c|c|c|}
\hline & Skills Group & Competency Sub-Group & Skills and Competences \\
\hline \multirow{2}{*}{ G } & \multirow{2}{*}{ Behavioral } & Intrapersonal & \\
\hline & & Interpersonal & \\
\hline \multirow{12}{*}{ 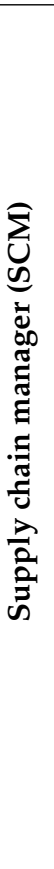 } & \multirow{7}{*}{ Business } & Business Administration & forecast future levels of business \\
\hline & & Economics & analyse economic trends \\
\hline & & Finance & $\begin{array}{l}\text { analyse market financial trends } \\
\text { apply for government funding } \\
\text { control financial resources } \\
\text { financial forecasting } \\
\text { forecast economic trends }\end{array}$ \\
\hline & & Integrated problem solving & \\
\hline & & Law and Regulations & $\begin{array}{l}\text { follow company standards } \\
\text { control commercial documentation }\end{array}$ \\
\hline & & Marketing & track price trends \\
\hline & & Quantitative and/or Statistics & carry out statistical forecasts \\
\hline & \multirow{5}{*}{ Ethics and environmental } & Environmental studies & \\
\hline & & Futures thinking & \\
\hline & & Sustainability & promote sustainable management \\
\hline & & Systems thinking & \\
\hline & & Value thinking & \\
\hline
\end{tabular}


Table 1. Cont.

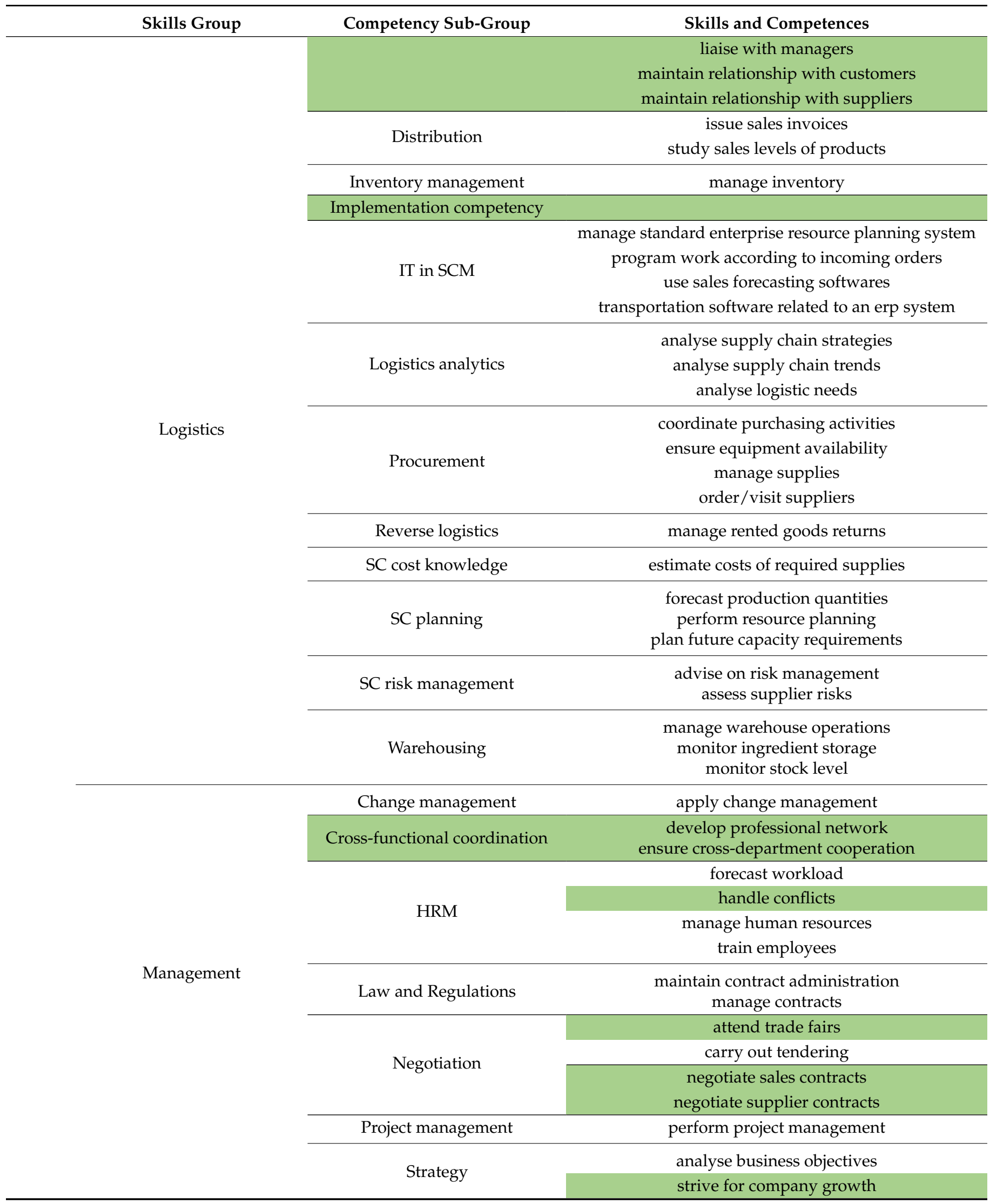


The multilingual classification of ESCO (European Skills, Competences, Qualifications and Occupations) aims to assign optional and/or essential skills or competences to occupations of ISCO (The International Standard Classification of Occupations) and to qualifications. It is a popular tool to execute job matching [50,51]. It was updated in August 2020. It contains 92 essential and optional skills, competences, and knowledge. The elements of this ontology were added to the previously determined categories based on their meaning. Specific expressions as knowledge areas, e.g., budget, purchasing, risk management, etc., determined their categories in the second column, e.g., Finance, Procurement, Risk in SCM, etc.

\section{Research Aim and Questions}

Product innovation creates new jobs due to the growing demands; meanwhile, process innovation has two-fold outputs: not efficient job roles disappear; meanwhile, new jobs appear. Predicting future situations in the labor market is a popular topic currently on which organizations, project teams, and experts work. Our research goal is to assist practitioners, lecturers, and decision makers with a method using text mining and analytics. They can extract actual labor market needs from job advertisements in the short term and analyse changes and trends in the long run. Learning outcomes and/or curricula can be modified based on this information depending on the degree of adapting sustainability concepts.

Sustainability is not a new concept, but an environmental disaster such as the COVID19 pandemic raises awareness among business leaders and stakeholders to make their company's operations greener or more sustainable. If so, higher education programs should meet these requirements.

Our research questions focus on detecting competency requirements in job ads to ground possible learning outcomes connected to sustainability. The validity and applicability of selected methods (text mining and processing, business analytics) can be verified based on these questions.

The research was guided by the following research questions:

- RQ1: What competencies containing hard and soft skills were required by the labor market in the field of supply chain management at different stages of the COVID-19 pandemic?

- $\quad$ RQ2: What positions and occupations require hard or soft skills related to sustainability in the field of supply chain management?

- RQ3: Was there any sign of being influenced by the COVID-19 pandemic in these positions?

The result of our research is a semi-automated method that can be an effective tool for monitoring labor market needs reflected by job ads. Knowledge of this output can help those working in higher education to place new concepts, knowledge to the fore or remove the outdated ones.

\section{Materials and Methods}

Job advertisements are beneficial signs of market needs even though they are not representative. They reflect the needs of labor market to a given degree. They can be used to gather information about the positions employers are looking for and the skills they require. In our work, we used the Indeed U.K. website to investigate employers' expectations of supply chain managers. U.K. labor market was chosen to demonstrate these methods. This country took serious steps for sustainability because it has already created a sustainability plan. We have selected two periods to analyse. This country went into the second lockdown in November, and it started to provide vaccines to its citizens very early in December. The reopening was delayed until March 2021, the effects of which are felt months later. We decided to collect job postings from November 2020 and, six months later, from May 2021. Not just sustainability-specific competences but effects caused by COVID-19 become detectable from these data sets due to this selection. We were 
also interested in whether we observe the effects of the COVID-19 virus outbreak in job advertisements, as several previously published studies have predicted that one of the consequences of the pandemic is the acceleration of sustainability processes.

Thus, we collected job ads using a Python crawler during the pandemic in November 2020 and again six months later in May 2021, when the epidemic had subsided, and the economy was starting to recover.

For our research, we used job advertisements in that all words of "supply chain manager" appeared. Supply chain managers were interpreted in a broader sense, meaning each position that these words were connected to. Duplicates were removed from the database. A total of 905 such jobs were found in November 2020 and 923 in May 2021. The job advertisements were classified by occupations from ISCO manually. The details of which are summarized in Table 2.

Table 2. Number of job advertisements was retrieved from the Indeed U.K. website. Online advertisements were collected over two periods in November 2020 and May 2021. (Source: prepared by the authors).

\begin{tabular}{ccc}
\hline Occupation & $\begin{array}{c}\text { Number of Jobs } \\
\text { November 2020 }\end{array}$ & $\begin{array}{c}\text { Number of Jobs } \\
\text { May 2021 }\end{array}$ \\
\hline Supply chain manager & 170 & 184 \\
Operations manager & 105 & 108 \\
Procurement manager & 191 & 141 \\
Warehouse manager & 99 & 112 \\
Other supply chain & 196 & 211 \\
professionals & 49 & 60 \\
Distribution manager & 19 & 23 \\
Forecast manager & 14 & 14 \\
Sales manager & 30 & 43 \\
Category manager & 15 & 5 \\
Quality manager & 9 & 6 \\
Manufacturing manager & 8 & 16 \\
Finance manager & $\mathbf{9 0 5}$ & $\mathbf{9 2 3}$ \\
Total & &
\end{tabular}

The downloaded job ads were first pre-processed, and irrelevant parts (company descriptions) were removed. The sentences containing at least 20 characters were processed, lemmatized, tokenized, and the part-of-speech tags were defined. These tasks were performed in Python programming language using different Python libraries such as pandas, re, and spacy. Then we used text-mining and text analytics methods to extract soft and hard skills needed by supply chain managers and related positions from job advertisements. The results of these analyses were interpreted in the light of our conceptual model (see Table 1) described in the previous section. Our aim was to show how to collect and determine expected soft and hard skills as competences in sustainability for supply chain managers. Text mining and text analytics supported our efforts. We used the Stata, Tableau, and Python programming languages.

The outputs of these methods had not highlighted green activities in job ads, but this phenomenon might be temporary. We wanted to hand these competences to curriculum developers and other stakeholders in a way that makes the curriculum more structured. We identified key activities for those working in the field of GSCM based on the green supply chain literature and summarized this in a process model. The dynamic process model shows the behavior of the process and its relations to the resources, roles, IT systems, data, and documents of the business environment. A structured representation of procedures highlights the relationships between the activities and the environmental objects. During the development of a curriculum, it is worth taking into account not only the knowledge required for the given procedures but also the relationships of the activities and their structure. We summarized how our methodology works in Figure 3. 


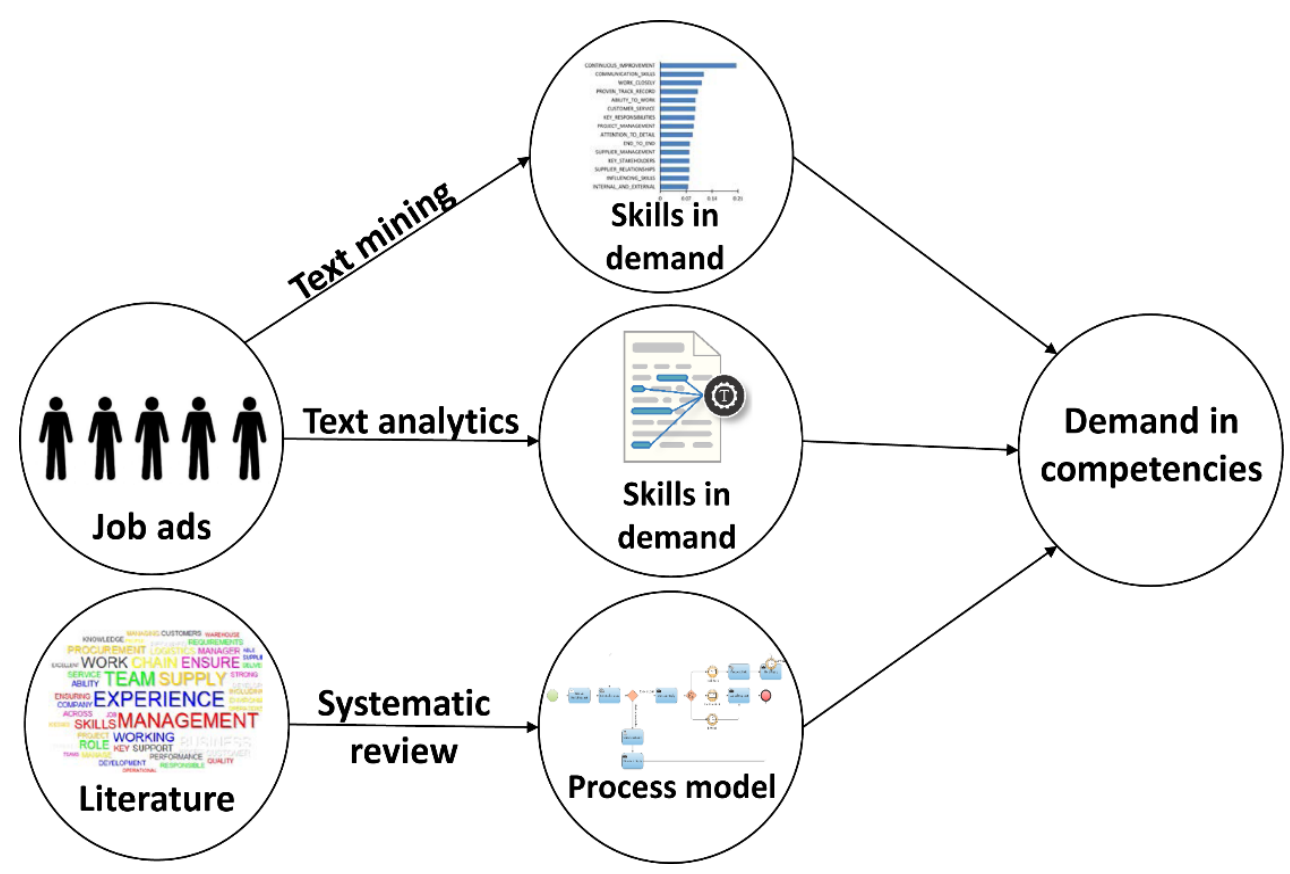

Figure 3. An overview of our research methodology (Source: prepared by the authors).

\section{Results}

\subsection{Determine Soft Skills Using Text-Mining Techniques}

Our first question was whether the eight key competences in sustainability in higher education [45] as "Systems thinking", "Futures-thinking", "Values-thinking" "Strategic- thinking", "Interpersonal", "Integrated problem-solving", "Implementation" "Intra-personal or selfawareness" were reflected in job advertisements. Thus, in the job advertisements, we first identified the most frequent and most important terms (with the highest term frequencyinverse document frequency (TF•IDF) value). The top 20 were summarized in Table 3 for both November 2020 and May 2021 data.

We need to mention that the second most important term in both periods was "continuous improvement", which featured in more than a fifth of the job ads collected, and "communication skills", which appeared in nearly a quarter of the ads. Among the top 30 most important terms, we find problem solving and attention to detail (data not shown).

To gain a better understanding of the most important phrases, we have carried out a topic extraction of the 2021 job advertisements. Based on the frequency of phrases, a factor analysis with varimax (Varimax rotation is a statistical technique used at one level of factor analysis as an attempt to clarify the relationship among factors. Rotation is computed in order to extract factors) All words with a factor loading higher than the criterion are then retrieved as part of the extracted topic. The 30 topics based on 2021 data are shown in Supplementary Figure S1.

The "continues improvement" topic is associated with words "CONTINUOUS; IMPROVEMENT; IMPLEMENT; IMPROVE; IMPROVEMENTS; PROCESSES; EXCELLENCE; PROCESS IMPROVEMENT; DEVELOP AND IMPLEMENT; IMPROVEMENT INITIATIVES". The list shows that continuous improvement in job ads is about improving processes, not about the individual's advancement. Thus, this overlaps with the "Futuresthinking" key competence, which means "to be able to iterate and continuously refine one's own futures thinking (visions, scenarios, etc.)" according to Brundiers et al. If we look at the words related to "communication skills", which are "SKILLS; COMMUNICATION; WRITTEN; ABILITY; EXCELLENT; ANALYTICAL; STRONG; EXCEL; EXPERIENCE", we notice that they partially cover the "Interpersonal" key competency, which is, among others, "different ways of knowing and communication" [45]. 
Table 3. The most frequent phrases in advertisements. From the text of the cleaned job ads collected in November 2020 and May 2021, the most common terms are extracted. The "\% cases" column shows the percentage of cases where the phrases occurred, and the "TF•IDF" column shows the importance of the phrase. The "Change" column shows how the frequency of each phrase has changed over the period, i.e., $\wedge$ means that the frequency of occurrence of the phrase has increased $\vee$ decreased, and the difference between the frequencies in periods A and B is given in brackets. (Source: prepared by the authors).

\begin{tabular}{|c|c|c|c|c|c|}
\hline Phrase & $\begin{array}{c}\% \text { Cases } \\
\text { November } 2020\end{array}$ & $\begin{array}{l}\text { \% Cases } \\
\text { May } 2021\end{array}$ & $\begin{array}{c}\text { TF•IDF } \\
\text { November } 2020\end{array}$ & $\begin{array}{l}\text { TF•IDF } \\
\text { May } 2021\end{array}$ & Change \\
\hline SUPPLY CHAIN & $72.49 \%$ & $68.36 \%$ & 231.1 & 287.4 & - \\
\hline $\begin{array}{l}\text { CONTINUOUS } \\
\text { IMPROVEMENT }\end{array}$ & $23.76 \%$ & $21.34 \%$ & 186.6 & 191.8 & - \\
\hline $\begin{array}{l}\text { CUSTOMER } \\
\text { SERVICE }\end{array}$ & $12.60 \%$ & $12.78 \%$ & 151.2 & 137.6 & $\vee(4)$ \\
\hline TRACK RECORD & $19.78 \%$ & $15.38 \%$ & 150.6 & 134.1 & $\vee(4)$ \\
\hline COMMUNICATION SKILLS & $26.08 \%$ & $24.05 \%$ & 148.9 & 148.5 & $\wedge(1)$ \\
\hline $\begin{array}{c}\text { PROJECT } \\
\text { MANAGEMENT }\end{array}$ & $14.25 \%$ & $12.13 \%$ & 141.3 & 129.2 & $\vee(3)$ \\
\hline $\begin{array}{l}\text { SUPPLY CHAIN } \\
\text { MANAGEMENT }\end{array}$ & $12.15 \%$ & $11.16 \%$ & 131.8 & 123.8 & $\vee(3)$ \\
\hline MANAGEMENT SKILLS & $16.13 \%$ & $11.59 \%$ & 128.4 & 111.4 & $\vee(14)$ \\
\hline HEALTH AND SAFETY & $11.49 \%$ & $12.35 \%$ & 126.8 & 150.8 & $\wedge(6)$ \\
\hline $\begin{array}{l}\text { OPERATIONS } \\
\text { MANAGER }\end{array}$ & $7.51 \%$ & $7.15 \%$ & 124.8 & 121.9 & $\vee(2)$ \\
\hline ABILITY TO WORK & $13.48 \%$ & $11.38 \%$ & 124.5 & 107.1 & $\vee(14)$ \\
\hline WORK CLOSELY & $12.71 \%$ & $10.29 \%$ & 123.6 & 110.6 & $\vee(11)$ \\
\hline $\begin{array}{l}\text { MANAGEMENT } \\
\text { EXPERIENCE }\end{array}$ & $14.92 \%$ & $15.82 \%$ & 122.3 & 140.1 & $\wedge(7)$ \\
\hline $\begin{array}{l}\text { MONDAY TO } \\
\text { FRIDAY }\end{array}$ & $14.59 \%$ & $15.49 \%$ & 117.1 & 121.8 & - \\
\hline $\begin{array}{l}\text { PROCUREMENT } \\
\text { MANAGER }\end{array}$ & $4.53 \%$ & $4.23 \%$ & 115.6 & 83.8 & $\vee(50)$ \\
\hline WORK REMOTELY & $15.36 \%$ & $16.58 \%$ & 113.1 & 119.1 & - \\
\hline TEAM MEMBERS & $9.50 \%$ & $9.97 \%$ & 112.4 & 106.7 & $\vee(11)$ \\
\hline $\begin{array}{l}\text { INTERNAL AND } \\
\text { EXTERNAL }\end{array}$ & $12.04 \%$ & $13.43 \%$ & 112.1 & 140.4 & $\wedge(14)$ \\
\hline JOB TYPES FULLTIME & $14.81 \%$ & $16.79 \%$ & 111.2 & 123.2 & $\wedge(8)$ \\
\hline $\begin{array}{l}\text { STRATEGIC } \\
\text { SOURCING }\end{array}$ & $10.39 \%$ & $3.79 \%$ & 110.2 & 82.1 & $\vee(46)$ \\
\hline
\end{tabular}

It is a sign of the COVID-19 pandemic that the term "health and safety" is so high on the importance list. It is worth noting that, in addition to "health and safety", the topic "life assurance" also appears in the list of extracted topics (see in Supplementary Figure S1).

Sex equality and sustainability are overlapping concepts that are also reflected in the UN Sustainable Development Goals (SDGs), as sex equality (Goal 5) and reducing inequalities (Goal 10) relate to equal opportunity. We would like to highlight that in the case of job advertisements in the "diversity" and "employer" extracted topics, both can be observed.

To explore connections between phrases, we used proximity analysis and hierarchical clustering based on the association strength coefficient, which measures the co-occurrence of items taking into account the possibility that two items will sometimes co-occur by 
chance. Figure 4 shows the 15 closest phases to "supply chain" in the two time periods studied, and Figure 5 shows the clusters of "supply chain" terms. It can be observed that the continuous improvement and communication skills analyzed above were very often associated with the "supply chain" in both periods, and it is not surprising that the algorithm also clustered them together.

A

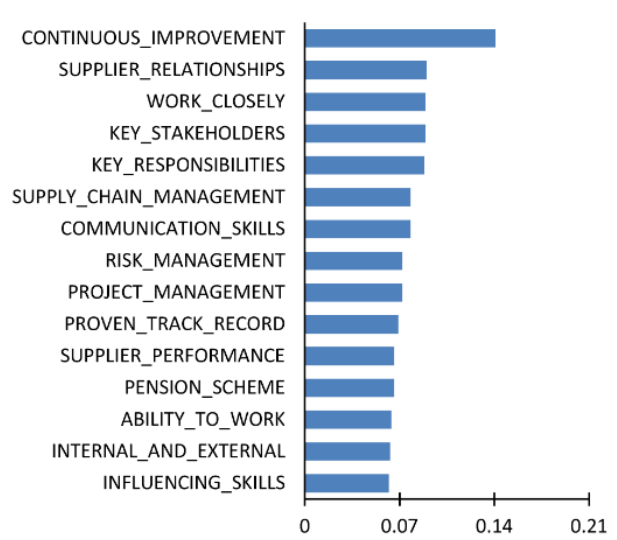

B Proximity phrases to supply chain (May 2021)

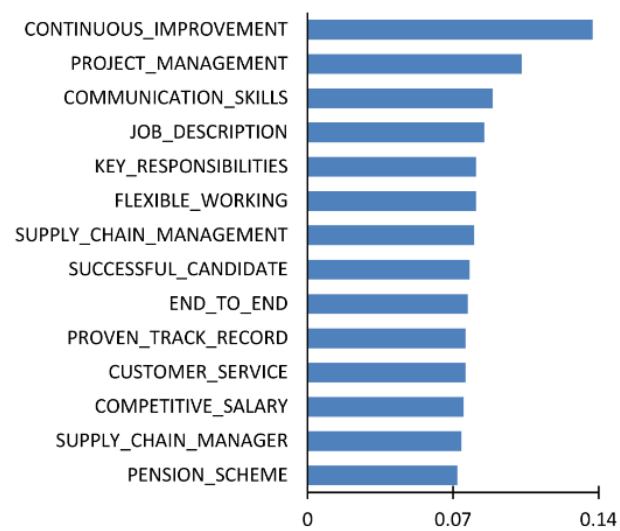

Figure 4. Proximity phrases to "supply chain" expression. Three or fewer word phrases were extracted from the job ads that occurred at least three times in the text. Proximity analysis was made on these phrases (using the paragraph as the frequency criteria) and the "supply chain" phrase was selected as the point of reference. Panel (A) shows the 15 phrases closest to the term "supply chain" based on data collected in November 2020. Panel (B) shows the 15 phrases closest to "supply chain" based on ads retrieved in May 2021. (Source: prepared by the authors).

A Cluster analysis - cluster of Supply chain (November 2020)

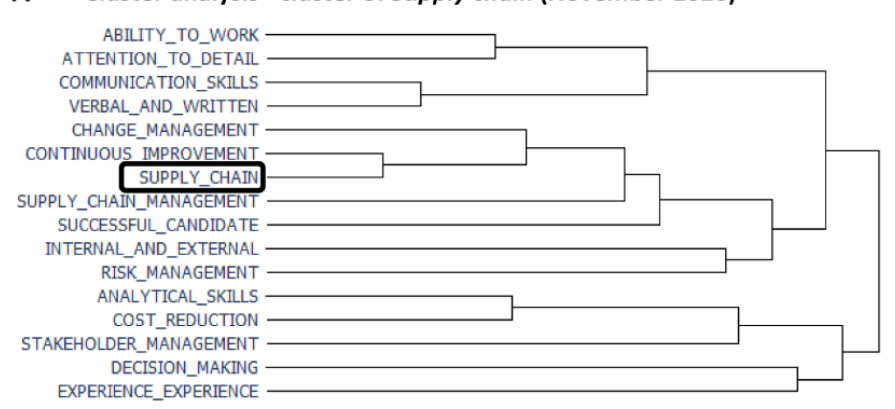

B Cluster analysis - cluster of Supply chain (May 2021)

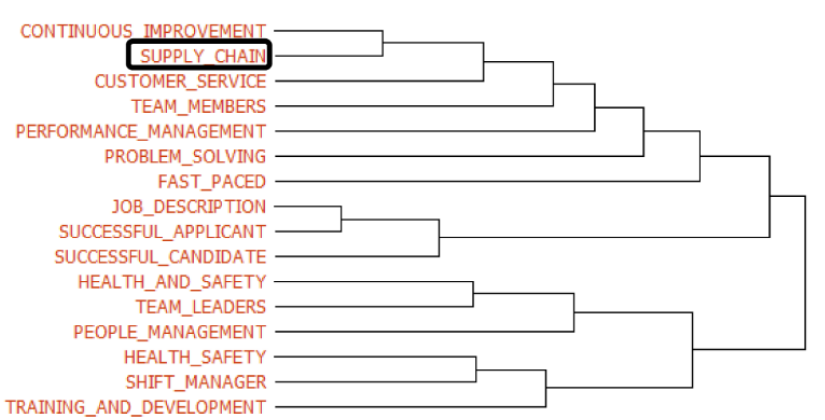

Figure 5. Supply chain cluster part of the dendrogram Average-linkage hierarchical clustering method was performed based on the similarity of the phrases extracted from job ads. Panel (A) shows the cluster containing the phrase "supply chain" out of the 84 clusters obtained from the November 2020 job ads (cophenetic correlation is 0.91). Panel (B) shows the cluster containing the term "supply chain" out of 80 clusters from the May 2021 data (cophenetic correlation is 0.92). (Source: prepared by the authors). 
Looking at the results of cluster analysis in Figure 5, it is noticeable that important sustainability competences such as analytical skills, verbal and written communication skills, and the ability of problem solving have been included in the supply chain cluster.

A sign of the COVID-19 pandemic could be that in November 2020, when closures were due to take place in the U.K., the "supply chain" cluster contained cost-reduction and change management phrases. In the case of the May 2021 data, when the epidemic has subsided, and the economy has started to reboot, these two phrases have disappeared from the cluster and have been replaced by "health and safety", "people management", "training and development", and "performance management".

A link analysis was performed on "continuous improvement" and "communication skills" phrases based on May 2021 data to visualize the connections between phrases using a network graph and to detect the underlying patterns (see Figure 6). The A panel of Figure 6 clearly shows that in addition to "continuous improvement", problem solving and verbal and written communication are clearly reflected in job advertisements, which are the basis for several key sustainability competences. Similarly, panel B, which explores concepts related to "communication skills", seems to strongly describe the Interpersonal, Intra-personal key competencies in sustainability.

A Link analysis of 'continous improvement' (May 2021)

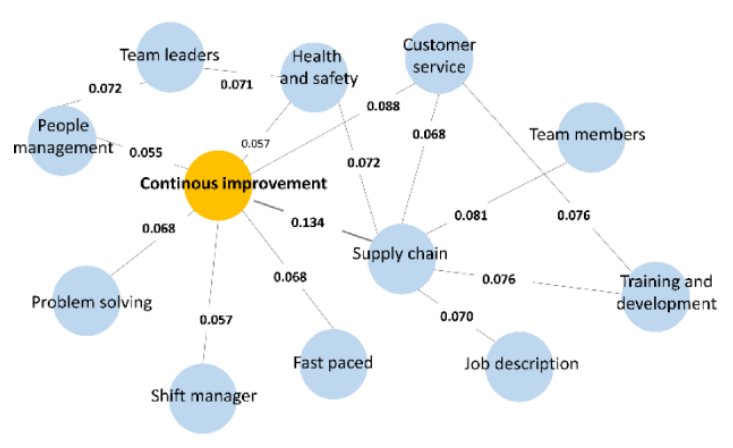

B Link analysis of 'communication skills' (May 2021)

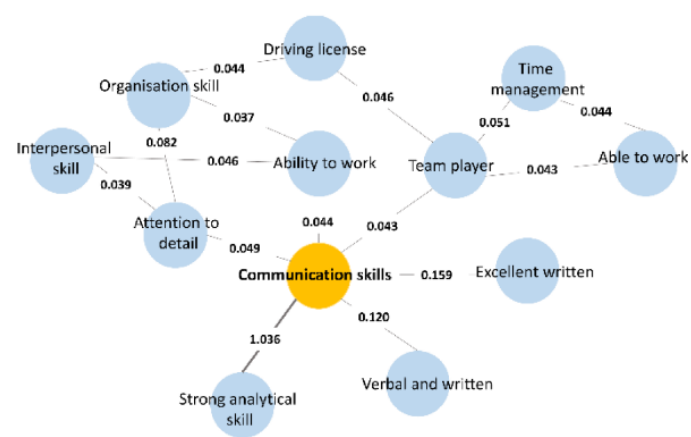

Figure 6. Link analysis of "continuous improvement" and "communication skills" based on data retrieved May 2021. The elements of a cluster containing the term "continuous improvement" or "communication skills" are shown, where the nodes are the terms in the cluster, and their relationship is represented by the lines connecting them. The higher the number, the stronger the connection. (Source: prepared by the authors).

Figure 6 shows that the expected knowledge and skills related to the sustainability competences required in the labor market must be inherently linked and integrated with each other.

\subsection{Determine Hard Skills Using Text Analytics}

In the previous analysis, we examined the skills required for supply chain managers based on the frequencies and statistical indicators in the advertisements, but we did not consider the grammatical structure of words and phrases. Having studied sustainability competence framework to supply chain managers (see Table 1), it is noticed that skills or competences from ESCO follow Bloom's taxonomy. The improved version of this taxonomy works as guidelines in training development. Six activities (Remembering, Understanding, Applying, Analyzing, Evaluating, Creating) determine the level of each competence to be acquired during learning [52]. Competences belonging to these activities are described by specific verbs [53]. A total of 34 verbs from the ESCO competences of supply chain managers are descriptors of Applying, Analyzing, Evaluating, and Creating tasks. Nevertheless, our previous experience [54] pinpointed that several tasks are listed in job ads that candidates should be able to achieve. An ideal candidate is supposed to be competent in performing these activities. In this sense, the tasks can also reflect labor market needs per se. These tasks can be extracted from job descriptions using their VERB... NOUN grammatical pattern. Every task is about doing (VERB) something (NOUN). Our 
method aims to collect these expressions from the sentences of job ads using Stanza (A Python NLP package for linguistic analytics) [55]. Sentences are separated based on their initial capital letters. The Table 4. presents descriptive statistics of our collection from both periods. A total of 36,669 expressions from 9349 sentences and 37,899 expressions from 9916 phrases were collected from the autumn and spring data sets. Tasks were not taken out from approximately $10 \%$ of sentences. Sentences with less than 31 characters were excluded from this investigation because the average length of ESCO competences is approximately 25 characters in our case.

Table 4. Descriptive statistics for data used in text analytics. Verbs and nouns were separated and stored in "lower_verb" and "lower_noun" variables. Moreover, the word before the noun was also identified as (probably) an adjective. They were added to the "lower_adj" variable. These terms were lemmatized to obtain a standard glossary approximately. (Source: prepared by the authors).

\begin{tabular}{lcc}
\hline \multicolumn{1}{c}{ Description } & November 2020 & May 2021 \\
\hline Total number of job ads & 905 & 923 \\
Total number of sentences & 9349 & 9916 \\
Extracted expression $\left(<\mathrm{VERB}>{ }^{*}<\mathrm{NOUN}>\right.$ ) & 36,669 & 37,899 \\
Sentences that expressions were not extracted & 1662 & 1690 \\
from (skipped sentences) & 702 & 642 \\
Skipped sentences with less than 31 characters & $10.3 \%$ & $10.1 \%$ \\
Ratio of skipped sentences & & \\
\hline
\end{tabular}

In the previous section, the text-mining methods were used to extract and analyse general patterns of skills from job ads. This approach revealed that it is very suitable for gaining insights into soft skills required by the labor market in supply chain management. ESCO ontology and Bloom's taxonomy discovered that the $<\mathrm{VERB}>^{*}<\mathrm{NOUN}>$ pattern, where * replace any expressions, harmonizes with the formulation of hard/technical skills.

The second research question is about positions and occupations. As mentioned, all positions from job ads were aligned to the occupations from ESCO (see in Table 1). Supply chain managers and operations managers were selected from them to investigate how their competences, especially in sustainability, are evolving in time. The reason behind this selection is that supply chain managers are in the group of new and emerging green occupations [15], and operations managers are involved in green projects [56].

Supplementary Figure S2 shows competences occurring in at least seven job postings at both occupations. Expressions from some job ads did not suit this purpose, so these job ads were not investigated further. A total of 98 (93\% of operations managers) and 154 (91\% of supply chain managers) job ads remained in the autumn data set. A total of 101 (94\% of operations managers) and 163 (90\% of supply chain managers) remained in our spring data set. These competences were assigned to the relevant categories of our conceptual model (see Table 1). It is worth noticing that sustainability was not in the focus of advertising companies in none of the COVID-19 stages. Competences could be connected to sustainability in an indirect manner.

- Interpersonal competency was identified based on the need for communication, interpersonal, leadership, and written communication skills, working under pressure and in some kind of environment;

- $\quad$ Futures thinking competency was detected by DRIVE (CONTINUOUS, SUSTAINABLE, PROCESS ETC) IMPROVEMENT and IDENTIFY OPPORTUNITY;

- Integrated problem-solving was discovered by RESOLVE (USER, SYSTEM, COMPLEX, and REPAIR ISSUE). The last issue indicates the appearance of reverse logistics;

- Implementation competency was discovered by DEVELOP SOLUTION, DELIVER SOLUTION and PROVIDE SOLUTION. The solution can be technological, not just environmental or sustainable, but the same skills, such as creativity, need to implement them. ENSURE ENVIRONMENTAL PROCESS and MANAGE SUSTAINABLE PROCESS were mentioned within the logistics context. 
Table 5 presents that job ads highlighted interpersonal and futures-thinking competencies versus integrated problem solving or implementation competency. Additional tasks appeared in a more detailed manner in the job ads from May 2021 than ones from November 2020. IT competences such as USE COMPUTER, ERP, FOLLOW, and MANAGEMENT SYSTEM were described in the spring set, while SAP EXPERIENCE was only on our list in the autumn set.

Table 5. Competences required by the labor market during a serious COVID-19 period and one of the reopening. The percentage shows proportions of job ads in that these competences were revealed by descriptors. Total percentage does not equal $100 \%$ because more than one competence is required to fill jobs. Green background indicates the top 7 competences (not including requirements). SCM stands for supply chain manager, and OM stands for operation manager. (Source: prepared by the authors).

\begin{tabular}{|c|c|c|c|c|c|c|}
\hline Competence & $\begin{array}{c}\text { SCM } \\
\text { \% Cases } \\
\text { November } 2020\end{array}$ & $\begin{array}{c}\text { SCM } \\
\% \text { Cases } \\
\text { May } 2021\end{array}$ & $\begin{array}{c}\text { SCM } \\
\text { Change }\end{array}$ & $\begin{array}{c}\text { OM } \\
\text { \% Cases } \\
\text { November } 2020\end{array}$ & $\begin{array}{c}\text { OM } \\
\% \text { Cases } \\
\text { May } 2021\end{array}$ & $\begin{array}{c}\text { OM } \\
\text { Change }\end{array}$ \\
\hline $\begin{array}{c}\text { QUALITY } \\
\text { MANAGEMENT }\end{array}$ & $12.34 \%(1)$ & $5.83 \%(7)$ & $\vee(6)$ & $8.67 \%(9)$ & $9.41 \%(5)$ & $\wedge(4)$ \\
\hline STRATEGY & $8.77 \%(2)$ & $7.36 \%(5)$ & $\vee(3)$ & $12.24 \%(2)$ & $8.91 \%(7)$ & $\vee(5)$ \\
\hline $\begin{array}{l}\text { INTERPERSONAL } \\
\text { COMPETENCY }\end{array}$ & $8.05 \%(3)$ & $8.59 \%(2)$ & $\wedge(1)$ & $7.14 \%(11)$ & $10.89 \%(3)$ & $\wedge(8)$ \\
\hline COLLABORATIONS & $7.86 \%(4)$ & $10.15 \%(1)$ & $\wedge(3)$ & $14.16 \%(1)$ & $10.52 \%(4)$ & $\vee(4)$ \\
\hline $\begin{array}{c}\text { FUTURES-THINKING } \\
\text { COMPETENCY }\end{array}$ & $7.79 \%(5)$ & $4.6 \%(14)$ & $\vee(9)$ & $9.18 \%(8)$ & $8.42 \%(8)$ & - \\
\hline DISTRIBUTION & $7.79 \%(6)$ & $7.36 \%(4)$ & $\wedge(2)$ & $12.24 \%(4)$ & $13.86 \%(1)$ & $\wedge(3)$ \\
\hline $\begin{array}{c}\text { SC COST } \\
\text { KNOWLEDGE }\end{array}$ & $7.14 \%(7)$ & $4.91 \%(11)$ & $\vee(4)$ & $0 \%$ & $6.93 \%(10)$ & - \\
\hline REQUIREMENTS & $6.76 \%(8)$ & $7.80 \%(3)$ & $\wedge(5)$ & $12.04 \%(5)$ & $12.87 \%(2)$ & $\wedge(3)$ \\
\hline LOGISTICS & $5.84 \%(9)$ & $5.40 \%(10)$ & $\vee(1)$ & $9.52 \%(7)$ & $7.72 \%(9)$ & $\vee(2)$ \\
\hline MANAGEMENT & $5.84 \%(10)$ & $5.62 \%(8)$ & $\wedge(2)$ & $12.24 \%(3)$ & $9.11 \%(6)$ & $\vee(3)$ \\
\hline SC PLANNING & $5.19 \%(11)$ & $0 \%$ & - & $0 \%$ & $0 \%$ & - \\
\hline $\begin{array}{c}\text { LOGISTICS } \\
\text { ANALYTICS }\end{array}$ & $5.19 \%(12)$ & $4.19 \%(15)$ & $\vee(3)$ & $0 \%$ & $0 \%$ & - \\
\hline $\begin{array}{c}\text { INTEGRATED } \\
\text { PROBLEM-SOLVING }\end{array}$ & $4.55 \%(13)$ & $4.29 \%(16))$ & $\vee(3)$ & $8.16 \%(10)$ & $0 \%$ & V \\
\hline $\begin{array}{l}\text { IMPLEMENTATON } \\
\text { COMPETENCY }\end{array}$ & $4.55 \%(14)$ & $4.29 \%(17)$ & $\vee(3)$ & $7.14 \%(12)$ & $6.93 \%(11)$ & $\wedge(1)$ \\
\hline $\begin{array}{c}\text { FUTURES } \\
\text { THINKING/ } \\
\text { SUSTAINABILITY }\end{array}$ & $0 \%$ & $0 \%$ & - & $11.22 \%(6)$ & $0 \%$ & - \\
\hline $\begin{array}{c}\text { LOGISTICS/ } \\
\text { SUSTAINABILITY }\end{array}$ & $0 \%$ & $6.13 \%(6)$ & $\wedge(6)$ & $0 \%$ & $0 \%$ & - \\
\hline IT IN SCM & $0 \%$ & $4.91 \%(13)$ & $\wedge(13)$ & $0 \%$ & $0 \%$ & - \\
\hline BUSINESS & $0 \%$ & $5.52 \%(9)$ & $\wedge(9)$ & $0 \%$ & $0 \%$ & - \\
\hline $\begin{array}{c}\text { LOGISTICS/ } \\
\text { ENVIRONMENTAL } \\
\text { STUDIES }\end{array}$ & $0 \%$ & $4.91 \%(12)$ & $\wedge(12)$ & $0 \%$ & $0 \%$ & - \\
\hline
\end{tabular}

The analyses of the two COVID stages (second lockdown in November 2020 and reopening in May 2021) proclaim that advertising companies needed supply chain managers competent in "ensuring compliance and standard", "developing strategy", "working in defense, fast paced environment and under pressure", "communication especially written communication and influencing skill", "leading team, establishing relationship, working with partners", "identifying opportunities", "ensuring delivery" and "reducing cost" prominently. They required operations managers proficient in "developing team and 
maintaining relationship", "developing plan", "making decision", "ensuring delivery", "driving continuous, operational, sustainable improvements", "managing operation and providing support", and "identifying opportunities" during the intensive COVID-19 period (second lockdown). In the phase of reopening, there were no serious changes in the composition of these competences, but the focus has shifted to leading teams from establishing relationships a little bit at supply chain managers. Collaborations, ensuring delivery, "managing - complaint, control, international, Kanban, planning, sustainable etc-processes" and developing strategy were put into the focus instead of quality management, reducing cost and identifying opportunities. The need for interpersonal competences was typical for both periods.

Meanwhile, ensuring delivery, "working in fast paced environment, under pressure and written communication skills as interpersonal competences", "ensuring compliance and standards" received more attention instead of developing plan, making decision, managing process at the operation managers. "Developing team and maintaining relationship" and "driving continuous, process and performance improvement" remained as prominent competences. Although our data set is not representative, we can detect the signs of such phenomena that are worth analyzing deeper. It is worth noticing that job ads reflected that quality assurance, opportunities, improvement options, partner relationships, cost reduction, and timely delivery meant the escape from situations caused by the lockdown in 2020.

Sustainability was mentioned as one of the improvement options (see in Figure 7). In conclusion, it was examined how to appear sustainable in our collection of expressions. Only 2.2\% of job ads held information about sustainability in November 2020 and $2.9 \%$ in May 2021. The concepts were connected to 7 occupations out of 12 in 2020 and 9 out of 13 in 2021. Sustainable agenda, business, practice, and value were mentioned in at least two different job postings in 2020 and sustainable future, material, practice, relationship, and solution in 2021.
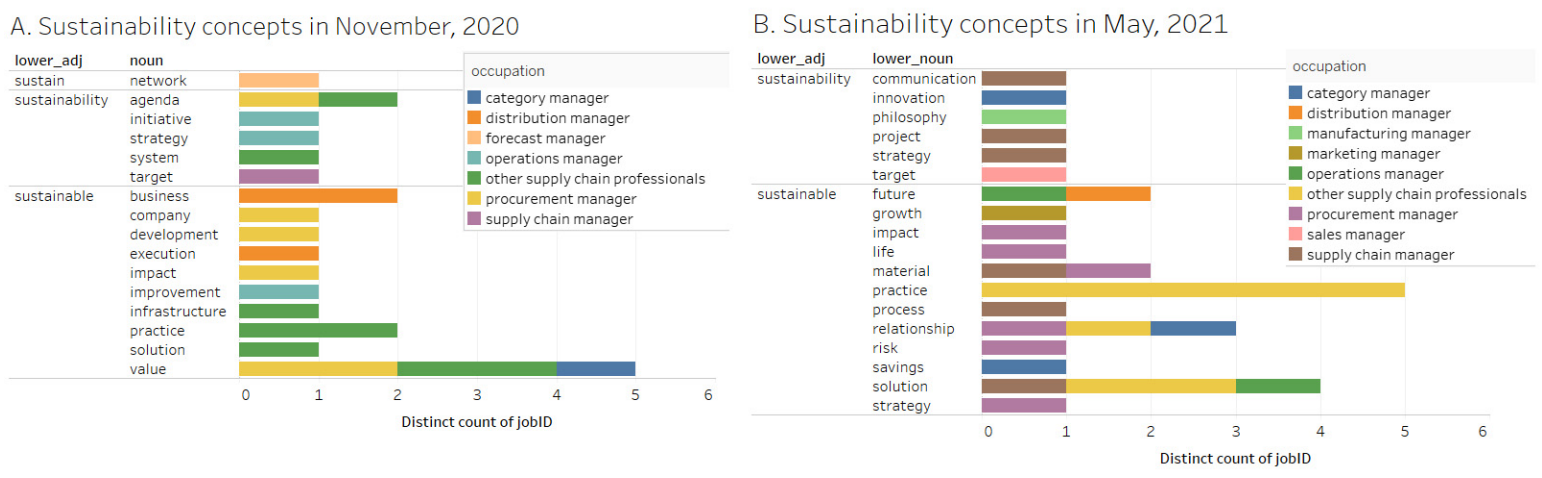

Figure 7. Sustainability concept (Source: prepared by the authors).

Waste management is an important green activity. Supplementary Figure S3 shows that in November, waste management was only associated with operations and procurement managers, but in May, it was also associated with other occupations. Other examinations can be carried out in Tableau workbooks uploaded as supplementary materials.

Concepts from green operations (repair, refurbish, remanufacturing, and disassembly) (see Figure 2) were checked in job ads directly. Repair was mentioned in 13 out of 905 in the autumn time period and 19 out of 923 in the spring time period; meanwhile, refurbish was in one case of 905 ads in November 2020 and 6 of 923 ads in May 2021. The other two concepts, remanufacturing and disassembly, were missing from job ads. Overall, the specific concepts of green SCM such as repair, remanufacture, dismantling, and refurbishment do not appear significantly in job advertisements. We therefore turned to the business process methodology to add further insights to the analytical power of text mining and text analytics. 


\subsection{Process Model Based on Literature}

Based on the literature, we explored the most important activities in the field of GSCM. Employees must perform these procedures in their work. They must have the appropriate competence to fulfill these tasks. A structured representation of procedures highlights the relationships between activities. During the development of a curriculum, it is worth taking into account not only the knowledge required for the given procedures but also the relationships of the activities and them building of each other.

We focus more on green manufacturing and remanufacturing and the reverse logistics within green operations. In the supply chain process, the steps and the products move toward the customer. In the case of reverse logistics, the resource goes from the customer to the distributor or to the manufacturer. The Reverse Logistics Executive Council defines reverse logistics as "the process of moving goods from their typical final destination to another point, for the purpose of capturing value otherwise unavailable, or for the proper disposal of the products" [57]. The customer returns the defective product. The manufacturing company has to organize shipping of the defective product, testing it, disposing or disassembling, repairing, recycling the product. The product travels in reverse through the supply chain network in order to preserve any use from the defective product.

We created the structure of the reverse logistics activities in the ARIS business process modeling tool (https: / / www.ariscommunity.com/aris-express [accessed on 15 June 2021]). The dynamic model shows (see Figure 8) not only the behavior of the process but how it relates to the resources, data, and functions of the business environment.

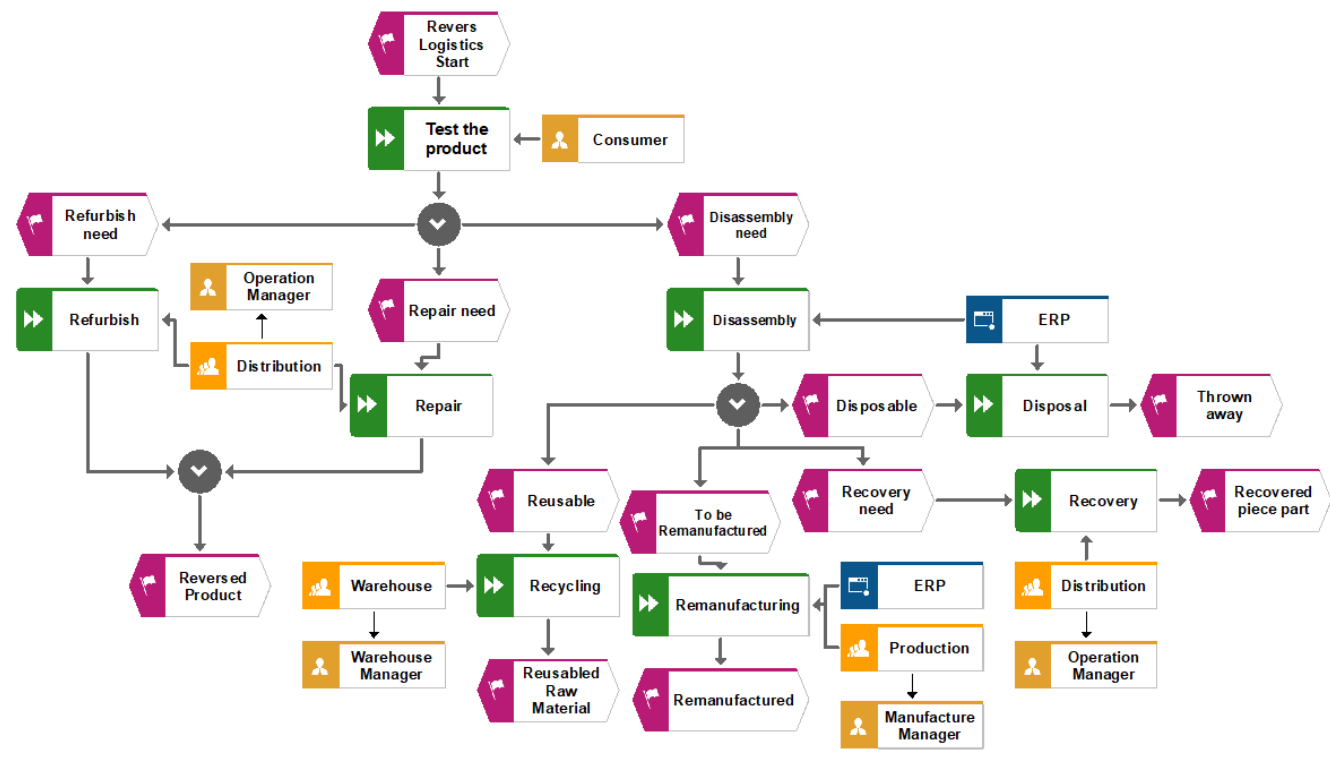

Figure 8. The green manufacturing and remanufacturing ARIS model (Source: prepared by the authors).

Green manufacturing aims to reduce the ecological burden by using appropriate materials and technologies while remanufacturing refers to an industrial process in which threadbare products are restored to a new state [58]. Green manufacturing generates minimum waste during production and reduces environmental pollution using techniques for minimum energy and resource consumption in order to reduce the use of dangerous or restricted materials during manufacturing $[59,60]$. Product or material recovery refers to the set of activities designed to reclaim value from a product at the end of its useful life. Authors categorize the recovery differently; for example: as a combination of remanufacture, reuse, and recycle [61] or repair, refurbish, remanufacture, cannibalize, and recycle [62]. Recycling is performed to retrieve the material content of used and non-functioning products, mainly driven by economic and regulatory factors [63]. The purpose of repair is to return used products to "working order". The quality of repaired products is generally lower than the quality of new products. The purpose of refurbishing is to bring used products up to a 
specified quality [64,65]. Disassembly is a systematic method of separating a product into its constituent parts, components, subassemblies, or other groupings [66]. An important aspect of disassembly is to find efficient disassembly process scheduling [65,67].

The remanufacturing process is more complex than the primary production process of the same product. The used or broken-down product must first be inspected to assess the feasibility of reusing or remanufacturing. In the case of recovery, the material or product should be repaired and refurbished or disassembled, and the components are reprocessed or substituted with new or reconditioned parts. All components are then re-assembled into the remanufactured product.

\section{Discussion}

A data-driven approach based on text-mining, text analytics, and business process modeling techniques was presented to extract information from external sources to support curriculum developers and stakeholders in developing, improving training programs or curricula. We focused on detecting how competences in sustainability can be retrieved from job ads. Labor market needs are one of these sources, and surveying opinions of alumni, employers also can generate useful inputs to develop curricula and training programs. These surveys can only be conducted periodically, but job advertisements can provide information on an ongoing basis. Job ads provide valuable insights to curriculum developers despite their limitations [16]. Focus groups, surveys can be conducted to complement or validate the results. Knowledge areas not emphasized by job ads were added to this analysis in a structured format with developing a business process model from relevant literature. We also developed a conceptual model for supply chain managers' competences in sustainability based on previous competence frameworks [44-47]. The outputs received from text mining and semantic-based text analytics were interpreted in the light of our model. These resulted competences can serve as input to outcomebased training or curricula development or renewal. The research questions reflect the information needs of these curriculum developers.

Our first question was to determine what competencies containing hard and soft skills were required by the labor market in the field of supply chain management at different stages of the COVID-19 pandemic. Our results showed that soft skills such as interpersonal skills, future thinking, integrated problem solving, implementation competences were easily identified in job advertisements, while hard skills such as ensuring environmental processes and managing sustainable processes were only mentioned in both time periods studied. We did not see a sharp difference in the sustainability competences required by the labor market in the two time periods studied, but COVID-19 effects were clearly identified. "Cost reduction" and "change management" phrases can be discovered during lockdown. However, when the epidemic subsided and the economy recovered, these two terms disappeared and were replaced by "health and safety", "people management", "training and development", and "performance management".

To answer our second research question, we studied what positions and occupations require hard or soft skills related to sustainability in the field of supply chain management. Supply chain managers and operations managers were selected to scrutinize their competences appeared in job ads. Expressions collected from $90 \%$ of original data sets were applied. It turned out that the soft skills identified in answering the previous research question, such as forward-thinking, integrated problem solving, etc., could be easily identified for both positions, and the hard skills were more likely to appear only at the level of mention. However, these competences were emphasized to different degrees by supply chain managers and operations managers. Sustainability concepts (value, practice, future, etc.) were mentioned in the job ads but not in a significant manner. Several occupations involved managing waste or wastage, but these tasks concentrated on a smaller group of occupations in 2021. Sustainability concepts (value, practice, future, etc.) were mentioned in the job ads but not in a significant manner. 
Other researchers have also investigated the presence of sustainability competences in addition to the commonly expected competences in job advertisements in supply chain management-related professions. Their results showed that sustainability skills were perceived as an important but less possessed skill among business analysts [25], interpersonal skills are more important while reverse and green logistics are less important skills to fulfill a logistics manager position [29] and skilled functional managers have a greater influence on sustainable management than general managers in terms of finding a balance between economic, social and environmental aspects [27]. Although our findings are similar to them, using the competency framework we developed allowed us to obtain a more detailed picture of the requirements for sustainability-related competencies.

In response to our third research question, we investigated whether there was any sign of being influenced by the COVID-19 pandemic in these positions. Our analysis showed that there was a shift within the competence sets. It is noteworthy to observe that the job postings reflected that quality assurance, opportunities, development opportunities, partnerships, cost reduction, and on-time delivery were the remedies for the situations caused by the closures. Procurement managers were supposed to identify opportunities during the second closure, but their importance declined during the reopening phase. The reason for this may be that this is a transferrable skill, the importance of which came to the fore during the pandemic period to keep the workforce balanced [30]. As mentioned in response to the first research question, there was no major difference in sustainability concepts between the two periods. Job advertisements after the reopening showed a slightly positive picture. This phenomenon again requires a deeper analysis due to the low number of hits.

Another important finding is that green SCM activities were not significantly included in either the competency frameworks or job advertisements. The aim of the research was to provide input in a structured way to refresh learning materials or learning outcomes. The modeling of green SCM operations was selected to complement the results of the analytical methods. The process model makes it easy for curriculum developers to see which steps need to be taught first, as knowledge of these is necessary to understand the next step in the process. For example: learners need to understand how to test products to decide whether to repair, refurbish or disassemble them. For example: students need to understand how to test products in order to decide which activity should be executed after that (repair, refurbish, or disassembly). In addition, the process model provides the possibility to link the steps to responsible, managerial roles and IT systems. These inputs help to tailor the learning programs and materials to the appropriate sessions and to determine which IT systems should be presented there. It is clear that digital technologies play a key role in disseminating and transferring this knowledge to people around the world.

\section{Conclusions}

In response to the growing need to find new techniques to promote a paradigm shift toward sustainable development, this work proposes a method to help curriculum developers and decision makers assess labor market needs in the area of sustainability skills and competences. This method can be used to collect skills from job advertisements and analyses not only the skills extracted but also their context, which helps to gain a deeper understanding of the skills required in the labor market. The methodology also incorporates a business process methodology, which complements the competences not yet present in the job advertisements but relevant for sustainability.

Our results also indicated that digital support is needed to ensure that the sustainability goals are widely reached. MOOC courses can support the development of hard skills, while digital communication platforms such programs as MS Teams or Zoom can support the development of soft skills. Learning analytics can support outcome-based teaching by providing students with personalized feedback on where they are in the curriculum and what they need to develop. 
Although our study was able to address some aspects of labor market expectations of sustainable competences, a weakness of our work is that specific concepts of green processes and related hard skills could not be significantly retrieved from job advertisements.

However, this paper presented that our data-driven approach is suitable to collect competences in sustainability from job ads, analyse the correlations, relationships, and context of these competences. The limitation stems from the low number of sustainability terms in advertisements. Text mining and text analytics require a sufficient number of terms to draw meaningful conclusions. Our future plans include applying our methodology to a broader, multi-country, representative collection of job advertisements and positions. Such wider, better-controlled experiments would be able to reveal fine differences in a very precise manner on sustainable competences. The process of our data-driven approach is independent of the job postings, repetitive, and can be automated. These features ensure that stakeholders, decision makers at universities will be able to monitor the sustainability needs of supply chain management positions continually with a system relying on this method.

Supplementary Materials: The following are available online at https://www.mdpi.com/article/10 $.3390 /$ su13179977/s1, Figure S1: List of extracted topics of Job advertisements in May 2021, Figure S2: Competences of supply chain manager versus operation manager. Figure S3: Waste management in November 2020 and May 2021

Author Contributions: Conceptualization, S.F., I.S., K.T.; methodology, S.F., I.S.; data curation S.F., I.S.; writing—original draft preparation, S.F., I.S., K.T.; writing—review and editing S.F., I.S.; visualization, S.F., I.S. All authors have read and agreed to the published version of the manuscript.

Funding: Institute of Information Technology, Corvinus University of Budapest.

Institutional Review Board Statement: Not applicable.

Informed Consent Statement: Not applicable.

Data Availability Statement: Not applicable.

Conflicts of Interest: The authors declare no conflict of interest.

\section{References}

1. Sachs, J.; Schmidt-Traub, G.; Mazzucato, M.; Messner, D.; Nakicenovic, N.; Rockström, J. Six transformations to achieve the SDGs. Nat. Sustain. 2019, 2, 805-814. [CrossRef]

2. Owens, T.L. Higher education in the sustainable development goals framework. Eur. J. Educ. 2017, 52, 414-420. [CrossRef]

3. Killen, R. Outcomes-Based Education: Principles and Possibilities; University of Newcastle: Callaghan, Australia, 2000.

4. Spady, W.G. Outcome-Based Education: Critical Issues and Answers; American Association of School Administrators: Arlington, VA, USA, 1994.

5. Macayan, J.V. Implementing outcome-based education (OBE) framework: Implications for assessment of students' performance. Educ. Meas. Eval. Rev. 2017, 8, 1-10.

6. Ennis, M.R. Competency Models: A Review of the Literature and the Role of the Employment and Training Administration (ETA); Office of Policy Development and Research, Employment and Training, U.S. Department of Labor: Washington, DC, USA, 2008.

7. Stepanenko, V.; Kashevnik, A. Competence management systems in organisations: A literature review. In Proceedings of the 2017 20th Conference of Open Innovations Association (FRUCT), Saint Petersburg, Russia, 3-7 April 2017; pp. 427-433.

8. Irawan, I. The design of Spencer generic competency as a model for banking supervisors position specification in Surabaya. $J$. Econ. Bus. Account. Ventur. 2011, 14, 217-224. [CrossRef]

9. Rowe, C. Clarifying the use of competence and competency models in recruitment, assessment and staff development. Ind. Commer. Train. 1995, 27, 12-17. [CrossRef]

10. Hecklau, F.; Galeitzke, M.; Flachs, S.; Kohl, H. Holistic approach for human resource management in Industry 4.0. Procedia CIRP 2016, 54, 1-6. [CrossRef]

11. Grundke, R.; Jamet, S.; Kalamova, M.; Keslair, F.; Squicciarini, M. Skills and Global Value Chains: A Characterisation; OECD: Paris, France, 2017. [CrossRef]

12. Wikle, T.A.; Fagin, T.D. Hard and soft skills in preparing GIS professionals: Comparing perceptions of employers and educators. Trans. GIS 2015, 19, 641-652. [CrossRef]

13. Lippman, L.H.; Ryberg, R.; Carney, R.; Moore, K.A. Workforce Connections: Key "Soft Skills" That Foster Youth Workforce Success: Toward a Consensus Across Fields; Child Trends: Washington, DC, USA, 2015. 
14. Scorza, P.; Araya, R.; Wuermli, A.J.; Betancourt, T.S. Towards clarity in research on "non-cognitive" skills: Linking executive functions, self-regulation, and economic development to advance life outcomes for children, adolescents and youth globally. Hum. Dev. 2016, 58, 313. [CrossRef]

15. Bianchi, G. Sustainability Competences: A Systematic Literature Review; JRC Working Papers; IDEAS, 2020; Available online: https://ideas.repec.org/p/ipt/iptwpa/jrc123624.html (accessed on 28 June 2021).

16. Carnevale, A.P.; Jayasundera, T.; Repnikov, D. Understanding Online Job Ads Data; Technical Report; Georgetown University: Washington, DC, USA, 2014.

17. Schlee, R.P.; Karns, G.L. Job requirements for marketing graduates: Are there differences in the knowledge, skills, and personal attributes needed for different salary levels? J. Mark. Educ. 2017, 39, 69-81. [CrossRef]

18. Daneva, M.; Wang, C.; Hoener, P. What the job market wants from requirements engineers? An empirical analysis of online job ads from The Netherlands. In Proceedings of the 2017 ACM/IEEE International Symposium on Empirical Software Engineering and Measurement (ESEM), Toronto, ON, Canada, 9-10 November 2017; pp. 448-453.

19. Wyskwarski, M. Identification of Desired Project Manager Competence Using Text Mining Analysis; Zeszyty Naukowe Organizacja i Zarządzanie/Politechnika Ślaska: Gliwice, Poland, 2020; pp. 735-749.

20. Fareri, S.; Fantoni, G.; Chiarello, F.; Coli, E.; Binda, A. Estimating Industry 4.0 impact on job profiles and skills using text mining. Comput. Ind. 2020, 118, 103222. [CrossRef]

21. Wowczko, I.A. Skills and vacancy analysis with data mining techniques. Informatics 2015, 4, 31-49. [CrossRef]

22. OECD. Getting Skills Right: Assessing and Anticipating Changing Skill Needs; Organisation for Economic Co-Operation and Development OECD: Paris, France, 2016.

23. European Centre for the Development of Vocational Training. Online Job Vacancies and Skills Analysis: A Cedefop Pan-European Approach. 2019. Available online: https:/ / www.voced.edu.au/content/ngv:82496 (accessed on 15 June 2021).

24. Cammeraat, E.; Squicciarini, M. Burning Glass Technologies' Data Use in Policy-Relevant Analysis: An. Occupation-Level Assessment; OECD Publishing: Paris, France, 2021.

25. Richards, D.; Marrone, M.; Vatanasakdakul, S. What does an information Systems graduate need to know? A focus on business analysts and their role in sustainability. In Proceedings of the 22nd Australasian Conference on Information Systems, Sydney, Australia, 30 November-2 December 2011; pp. 1-10.

26. Szabó, I.; Vas, R. Vacancy mining to design personalized learning analytics for future employees. In Proceedings of the International Conference on Electronic Government and the Information Systems Perspective, Linz, Austria, 27-30 September 2021; pp. 58-69.

27. Walińska, E.; Dobroszek, J. The functional controller for sustainable and value chain management: Fashion or need? A sample of job advertisements in the COVID-19 period. Sustainability 2021, 13, 7139. [CrossRef]

28. Barbosa, M.W.; de Oliveira, V.M. The corporate social responsibility professional: A content analysis of job advertisements. J. Clean. Prod. 2021, 279, 123665. [CrossRef]

29. Cvetić, B.; Vasiljević, D.; Danilović, M. Competence requirements for logistics managers in the Republic of Serbia. Manag. Sustain. Bus. Manag. Solut. Emerg. Econ. 2017, 22, 37. [CrossRef]

30. Scarpetta, S.; Quintini, G.; Mullock, K. Skill Measures to Mobilise the Workforce during the COVID-19 Crisis; VOCED: Adelaide, Australia, 2020.

31. Sarkis, J. Greener Manufacturing and Operations: From Design to Delivery and Back; Routledge: London, UK, 2017.

32. Soda, S.; Sachdeva, A.; Garg, R.K. Literature review of multi-aspect research works carried out on the concept and implementation of GSCM. Int. J. Ind. Syst. Eng. 2016, 23, 223. [CrossRef]

33. Srivastava, S.K. Green supply-chain management: A state-of-the-art literature review. Int. J. Manag. Rev. 2007, 9, 53-80. [CrossRef]

34. Zhu, Q.; Sarkis, J.; Lai, K.-H. Confirmation of a measurement model for green supply chain management practices implementation. Int. J. Prod. Econ. 2008, 111, 261-273. [CrossRef]

35. Tseng, M.-L.; Islam, M.S.; Karia, N.; Fauzi, F.A.; Afrin, S. A literature review on green supply chain management: Trends and future challenges. Resour. Conserv. Recycl. 2019, 141, 145-162. [CrossRef]

36. Hashemi, S.H.; Karimi, A.; Tavana, M. An integrated green supplier selection approach with analytic network process and improved Grey relational analysis. Int. J. Prod. Econ. 2015, 159, 178-191. [CrossRef]

37. Srivastava, S.K. Profit driven reverse logistics. Int. J. Bus. Res. 2005, 4, 53-61.

38. Porter, M.E.; Van der Linde, C. Toward a new conception of the environment-competitiveness relationship. J. Econ. Perspect. 1995, 9, 97-118. [CrossRef]

39. Silvestre, B.S.; Ţîrcă, D.M. Innovations for sustainable development: Moving toward a sustainable future. J. Clean. Prod. 2019, 208, 325-332. [CrossRef]

40. Seles, B.M.R.P.; Jabbour, A.B.L.D.S.; Jabbour, C.J.C.; Latan, H.; Roubaud, D. Do environmental practices improve business performance even in an economic crisis? Extending the win-win perspective. Ecol. Econ. 2019, 163, 189-204. [CrossRef]

41. Liu, S.; Chang, Y.-T. Manufacturers' closed-loop orientation for green supply chain management. Sustainability 2017, $9,222$. [CrossRef]

42. Chu, S.H.; Yang, H.; Lee, M.; Park, S. The impact of institutional pressures on green supply chain management and firm performance: Top management roles and social capital. Sustainability 2017, 9, 764. [CrossRef] 
43. Rao, P.; Holt, D. Do green supply chains lead to competitiveness and economic performance? Int. J. Oper. Prod. Manag. 2005, 25, 898-916. [CrossRef]

44. Mageto, J.; Luke, R. Skills frameworks: A focus on supply chains. J. Transp. Supply Chain Manag. 2020, 14, 17. [CrossRef]

45. Brundiers, K.; Barth, M.; Cebrián, G.; Cohen, M.; Diaz, L.; Doucette-Remington, S.; Dripps, W.; Habron, G.; Harré, N.; Jarchow, M.; et al. Key competencies in sustainability in higher education-Toward an agreed-upon reference framework. Sustain. Sci. 2020, 16, 13-29. [CrossRef]

46. Davis, R.S.; Girth, A.M.; Stazyk, E.C. Social and technical determinants of perceived contract performance: Rules, autonomy, and ethics. Public Perform. Manag. Rev. 2016, 39, 728-755. [CrossRef]

47. ESCO. European Commission-European Data Portal; 2021. Available online: https://ec.europa.eu/esco/portal/home (accessed on 28 June 2021).

48. Macdonald, A.; Clarke, A.; Ordonez-Ponce, E.; Chai, Z.; Andreasen, J. Sustainability managers: The job roles and competencies of building sustainable cities and communities. Public Perform. Manag. Rev. 2020, 43, 1413-1444. [CrossRef]

49. Wiek, A.; Withycombe, L.; Redman, C.L. Key competencies in sustainability: A reference framework for academic program development. Sustain. Sci. 2011, 6, 203-218. [CrossRef]

50. Wong, L.P.; Yuen, M. career guidance and counseling in secondary schools in hong kong: A historical overview. J. Asia Pac. Couns. 2019, 9, 1-19. [CrossRef]

51. Kot, P.; Roznowski, B.; Ertelt, B.-J. Construction and validation of the life roles self-efficacy scale for young adults in school-to-work transition. Curr. Psychol. 2020, 2020, 1-13. [CrossRef]

52. Forehand, M. Bloom's taxonomy. Emerg. Perspect. Learn. Teach. Technol. 2010, 41, 47-56.

53. Armstrong, P. Bloom's Taxonomy; Vanderbilt University: Nashville, TN, USA, 2016.

54. Szabó, I.; Ternai, K.; Fodor, S. Competence Mining to Improve Training Programs. In Transactions on Petri Nets and Other Models of Concurrency XV; Koutny, M., Kordon, F., Pomello, L., Eds.; Springer Science and Business Media LLC: Berlin/Heidelberg, Germany, 2020; pp. 147-157.

55. Qi, P.; Zhang, Y.; Zhang, Y.; Bolton, J.; Manning, C.D. Stanza: A python natural language processing toolkit for many human languages. In Proceedings of the 58th Annual Meeting of the Association for Computational Linguistics: System Demonstrations, Online, 5-10 July 2020; pp. 101-108.

56. Chaplin, L.; O'Rourke, S.T. Could lean and green be the driver to integrate business improvement throughout the organisation? Int. J. Prod. Perform. Manag. 2018, 67, 207-219. [CrossRef]

57. Rogers, D.S.; Tibben-Lembke, R.S. Going Backwards: Reverse Logistics Trends and Practices; Reverse Logistics Executive Council: Pittsburgh, PA, USA, 1999.

58. Lund, R.T. Remanufacturing: The Experience of the United States and Implications for Developing Countries; The World Bank: Washington, DC, USA, 1984.

59. Van Hoek, R.I. From reversed logistics to green supply chains. Supply Chain Manag. Int. J. 1999, 4, 129-135. [CrossRef]

60. Zhu, Q.; Sarkis, J. Relationships between operational practices and performance among early adopters of green supply chain management practices in Chinese manufacturing enterprises. J. Oper. Manag. 2004, 22, 265-289. [CrossRef]

61. Johnson, M.R.; Wang, M.H. Planning product disassembly for material recovery opportunities. Int. J. Prod. Res. 1995, 33, 3119-3142. [CrossRef]

62. Thierry, M.; Salomon, M.; Van Nunen, J.; Van Wassenhove, L. Strategic issues in product recovery management. Calif. Manag. Rev. 1995, 37, 114-136. [CrossRef]

63. Stock, J.; Speh, T.; Shear, H. Many happy (product) returns. Harv. Bus. Rev. 2002, 80, 16-17.

64. Sundin, E.; Bras, B. Making functional sales environmentally and economically beneficial through product remanufacturing. J. Clean. Prod. 2005, 13, 913-925. [CrossRef]

65. Ferrer, G. On the widget remanufacturing operation. Eur. J. Oper. Res. 2001, 135, 373-393. [CrossRef]

66. Taleb, K.N.; Gupta, S.M. Disassembly of multiple product structures. Comput. Ind. Eng. 1997, 32, 949-961. [CrossRef]

67. Krikke, H.R.; Van Harten, A.; Schuur, P. On a medium term product recovery and disposal strategy for durable assembly products. Int. J. Prod. Res. 1998, 36, 111-140. [CrossRef] 